\title{
O livre jogo da linguagem poética em Friedrich Schlegel
}

Sílvia Faustino - UFBA

Pretende-se aqui propor a tese de que, em alguns de seus célebres escritos da fase romântica, Friedrich Schlegel apresenta, com relativa clareza e suficiente base textual, os princípios de uma concepção geral da linguagem poética como exposição de sentidos e significados que se constituem no livre jogo das representações anímicas. À luz de diretrizes conceituais do idealismo kantiano e do esforço para projetar um novo olhar nos modos de conceber a arte e a experiência artística, Schlegel consolida uma poética da interioridade do espírito e da expressão autônoma da subjetividade. $\mathrm{O}$ aspecto mais singular desse projeto consiste no fato de que, ao seu núcleo essencialmente idealista, mantém-se organicamente incorporado o conceito de "verossímil" - conceito este que, naquela época, estava profundamente vinculado à tradição das poéticas neoclássicas, às quais o romantismo é em geral contraposto. Sem aprofundar todas as consequências teóricas desse fecundo conceito que vem ocupar o centro da estética literária de Schlegel, pode-se, no entanto, mostrar que 
é com base nele que podemos entender em que sentido os românticos foram capazes de dizer que a filosofia, sem perder sua dignidade específica, pode aproximar-se da poesia quando atua pelo discurso.

A quem investiga o pensamento de Schlegel sobre a arte poética não escapa o papel fundamental da interioridade do espírito, de cujas profundezas a poesia deve ser extraída. É no interior do gênio que se forma e amadurece o universo a ser germinado "em cada mônada", assim como é nele que vive uma "multiplicidade de espíritos" e um "sistema completo de pessoas" (Schlegel, 1997, $121-1967,85)^{1}$. Os poemas sáficos, suprassumo do lirismo, "precisam crescer e ser encontrados" (Ibid., p. 119 -Ibid., p. 85). Aquilo que se forma e cresce no espírito do poeta, como um organismo em formação, é por ele encontrado e trazido à expressão - exatamente a mesma expressão que busca e alcança aquilo que também se formou e se desenvolveu no íntimo do leitor. É pela linguagem que a poesia efetua esse encontro entre a intenção de significar do poeta e a produção do sentido pela intuição do leitor. Na discussão entre amigos narrada na Conversa sobre a poesia, logo após a personagem Amália ter afirmado que é "em seu interior" que "todo espírito livre" deveria apreender diretamente o ideal e a harmonia, Ludovico, um dos interlocutores, declara o que poderíamos doravante considerar como uma ideia reguladora da concepção schlegeliana da

1 Os fragmentos das revistas Lyceum e Athenäum foram traduzidos por Márcio Suzuki; a indicação conterá o título da revista, o número do fragmento e a página do original da edição crítica consultada. Todos os fragmentos publicados em vida por Schlegel estão traduzidos para o português no livro $O$ dialeto dos fragmentos, com tradução, apresentação e notas de Márcio Suzuki, São Paulo, Iluminuras, 1997. Edição crítica consultada: Kritische Friedrich Schlegel Ausgabe, editada por Ernst Behler. Paderborn/Munique/Viena: Ferdinand Schöningh, vol. II (KAII). 
linguagem poética. Sem discordar de que o estofo do poético vem do espírito interior, ele afirma: "apenas pela exposição exterior [Darstellung nach außen], pode a representação interior [innere Vorstellung] tornar-se mais clara e completamente viva" (Id., 2016, p. 19 - 1967, p. 306). Ora, essa fala de Ludovico fornece o ponto de vista que permite definir a linguagem poética como uma forma de exposição [Darstellung] de representações [Vorstellungen] do ânimo ou do espírito. E pensando na integração da linguagem com a filosofia transcendental das representações do ânimo, poderíamos sugerir também que a essa atividade de expor possa corresponder um "livre jogo", no sentido kantiano do "sentimento do livre jogo dos poderes-de-representação" ou do "estado de um livre jogo das faculdades-de-conhecimento quando de uma representação" que "tem de poder ser universalmente comunicado"(Kant, 1980, p. 220). É nessa perspectiva que se pode dizer que a linguagem poética se liga a um livre jogo de representações.

Quando Schlegel menciona questões relativas à unidade, divisibilidade ou indivisibilidade da poesia e considera que "a maioria dos modos de representação do sistema cósmico da poesia é ainda tão grosseira e pueril quanto os antigos modos de representação do sistema astronômico antes de Copérnico" (Schlegel, 1967, p. 252), fica claro que ele ousa algo como uma revolução copernicana quanto ao pensamento acerca dos critérios até então vigentes do modo de conceber a poesia como um sistema. O que Schlegel espera do "sistema cósmico da poesia" são "modos de representação" que permitam tratar as expressões poéticas como formações insaturadas de sentidos, isto é, como formações não submetidas a regras determinadas por modos genéricos de composição. O problema que se coloca de maneira muito clara 
na Conversa sobre a Poesia é o seguinte: se a fantasia de um espírito livre provém de uma força espiritual indivisa, como o sistema da poesia poderia dividi-la e classificá-la em gêneros sem corromper a natureza integral dessa origem?

A saída desse problema, como nos aponta Márcio Suzuki, está numa das falas do mesmo Ludovico, anteriormente citado: a fantasia de um poeta "tem necessariamente de se limitar e dividir [beschränken und teilen] em virtude de sua própria atividade e por meio dela" (Susuki in, Schlegel, 1997, p. 15). Ou seja, limitação e divisão são necessárias, mas o ideal é que sejam instituídas em meio à própria atividade criadora, no processo simultâneo de invenção e de busca pelo modo mais adequado de "plasmar matéria literária em formas", como também diz Schlegel no fragmento em que compara o autor zeloso a um artesão em sua atividade fabril (Schlegel, 1967, p. 232). Ora, que a divisão e a limitação da fantasia se deem por assim dizer no calor da hora, não significa que os vínculos entre matéria e forma sejam arbitrários ou puramente contingentes. Pois, enquanto Darstellung que se produz passando, necessariamente, pela atuação de um receptor, a linguagem poética deve poder valer como convite à produção sempre atual do seu sentido possível, isto é, ela deve se oferecer como um estímulo permanente para a atuação recíproca das faculdades de representação. É assim que a obra de um poeta genial se torna capaz de fazer com que a "letra", enquanto "espírito fixado", possa vir a "libertar o espírito estabilizado" como uma "ação mágica" .

O princípio de autolimitação da expressão poética implica a

${ }^{2}$ Emprego os termos do fragmento 1229 de Philosophische Lehrjahre. Fragmente zur Philosophie, traduzido por M. Suzuki, in Dialeto dos Fragmentos, nota 220, p. 204. 
consciência de uma harmonia entre a matéria e a forma das representações. Tal princípio parece estar presente em tudo aquilo que se apresenta como poesia, desde alguns raros poemas nos quais este princípio atingiria seu ápice até a abundância de "esboços, estudos, fragmentos, tendências, ruínas e materiais poéticos", de que nos fala o fragmento 4 do Lyceum. Quando diz que há "tanta poesia e, no entanto, nada mais raro que um poema", Schlegel reconhece a dificuldade de se apreender com a linguagem "tanta" poesia, que existe como uma realidade indiscutível. Porém, mais do que enfatizar a precariedade de um mero instrumento, essas linhas apontam para a dificuldade na criação da expressão capaz de ao mesmo tempo conter e despertar, por sua simples ocasião, o jogo das representações interiores em nível similar de profusão e amplitude. Pois a linguagem funciona como um dispositivo de capturas e solturas de sentidos poéticos.

Na linha dessas considerações, convém lembrar as críticas de Schlegel aos procedimentos analíticos de interpretação, que projetam nas composições poéticas critérios externos de desmontagem, como se da soma de blocos parciais de significados se pudesse chegar à recomposição do sentido do todo. Essa estratégia resulta completamente inútil diante da simples constatação de que "na poesia cada todo bem pode ser metade, e cada metade pode no entanto ser propriamente todo" (Schlegel, 1967, p. 148). O teor analítico-matemático dos termos "metade" e "todo" se esvanece. Pois, quando aplicadas à poesia, em vez de quantificar, as noções de todo e metade parecem qualificar o sentido em termos de intenções de significar: a metade quer significar o todo e o todo, a metade. De acordo com isso, fica teoricamente inviabilizado qualquer tipo de correspondência entre a extensão material e objetiva dos sinais perceptíveis e aquilo 
que eles buscam significar. E porque a extensão material do signo linguístico não determina a extensão do sentido na poesia, "metade" e "todo" não significam quanta fixos e manipuláveis, do mesmo modo que a poesia não é a soma dos poemas e dos materiais poéticos (mais ou menos elaborados) que existem.

O fato é que nenhum método analítico de interpretação poderia captar a natureza da "reflexão poética" mencionada no célebre fragmento 116 da Athenäum. A fim de caracterizar minimamente essa difícil e polêmica noção, algumas observações de Walter Benjamin sobre o conceito de reflexão parecem ser de grande valia. Segundo ele, a reflexão é o conceito que se torna "a base do primeiro romantismo" (Benjamin, 2002, p. 31). Afirma também que nos escritos da época da Athenäum, isto é, no sentido próprio do primeiro romantismo, "o ponto central da reflexão é a arte e não o Eu", como teria sido para Fichte, para Novalis e para o próprio Schlegel em fase posterior (Ibid., p. $\left.46^{3}\right)$. No entender de Benjamin, para os primeiros românticos, a "pura essência da reflexão" se anuncia na "aparição puramente formal da obra"; por isso "a forma" é "a possibilidade da reflexão na obra" na medida em que é "a expressão objetiva da reflexão própria à obra" (Ibid., p. 78-79). Ora, é nessa mesma perspectiva que se revela promissora a visão da linguagem da poesia como Darstellung que possibilita a reflexão pelo despertar para o livre jogo das representações na produção dos sentidos. É notável como em Schlegel a constituição do sentido parece exigir

\footnotetext{
${ }^{3}$ Cito a passagem completa: "Seguindo Fichte, as Lições Windischmann determinam [acerca da reflexão] este ponto central, o absoluto, como o Eu. Nos escritos schlegelianos da época da Athenäum este conceito desempenha um papel menor, menor não apenas do que em Fichte, mas também do que em Novalis. No sentido primeiro romântico, o ponto central da reflexão é a arte e não o Eu".
} 
a reflexão mesmo em certos casos-limites nos quais os poemas se apresentam apenas como uma inscrição [Überschrift] - e não ainda como uma exposição [Darstellung] poética. São casos em que a expressão de algum modo falha, mas na qual ainda assim é possível encontrar uma indicação daquilo que o poeta "deveria expor" (Schlegel, 1967, p. 153). É como se a poesia comparecesse ali apenas como promessa não cumprida, e somente a reflexão de um leitor, imersa em expectativa, conseguisse pressentir um sentido possível, mas ainda ausente.

A ideia da poesia como expressão de uma interioridade espiritual possibilitada pela reflexão ganha especial relevo na declaração de que toda pessoa que é culta e se cultiva contém "um romance em seu interior" (Ibid., p. 156). Também no trecho do fragmento da 116 da Athenäum lê-se que "muitos artistas, que também só queriam escrever um romance, expuseram por acaso a si mesmos". Ora, é bastante notável que no mesmo fragmento em que admite a ideia de um "romance interior", Schlegel venha também salientar o fato de não ser "necessário" que aquele que o possui "o exteriorize ou escreva". Ironia à parte, o que importa é a ideia de que escrever é exteriorizar um interior - ao que se poderia acrescentar então que ler é um interiorizar a partir da escritura. E no limite comum entre esses atos está a linguagem expressiva como condição de possibilidade do encontro comunicativo. Ao dizer que não é "necessário" que essa vida espiritual seja escrita, estaria Schlegel reconhecendo uma dimensão literária - ou pré-literária - puramente espiritual e interior, que poderia seguir existindo independentemente de sua exteriorização? Se assim for, poderíamos falar de uma espécie de formação [Bildung] poética individual que, embora no silêncio, dimensiona a passagem da vida do espírito como se fosse um romance. 
Mesmo sem ser vertida em letra, a vida espiritual seguiria sendo vivida como narrativa passível de ser exteriorizada. Ora, é justamente por poder alcançar a interioridade privada e pessoal do leitor que a literatura pode ser fonte de autoconhecimento. Os romances são o paradigma da vida espiritual e contêm a sabedoria da vida; e a poesia pode ser considerada "a suprema e mais digna de todas as artes" porque, entre outras coisas, "somente nela dramas são possíveis" (Ibid., p. 185). Através da reflexão, dramas tão pessoais se apresentam em narrativas tão universais.

Ora, como a linguagem da poesia realiza o arco intuitivo e intencional que vai da exterioridade de um sinal às profundezas da vida espiritual? A fim de conferir um sentido plausível a essa pergunta no contexto dos escritos de Schlegel, examinemos o seguinte fragmento da Athenäum: "Aparência poética é jogo de representações, e jogo é aparência de ações." (Ibid., p. 180). Como se vê, o conceito de "aparência poética" é sumariamente identificado ao conceito de "jogo de representações". É preciso enfrentar o estilo criptográfico dessa afirmação a fim de tornar mais claro o conceito de aparência que, no contexto idealista, envolve sempre a ideia de receptividade - pois o que aparece, aparece para alguém. Pode-se dizer que o fragmento remete a Kant quando, na Crítica do Juizo, ele diz que a poesia "joga com a aparência [Schein], que efetua ao bel-prazer, sem entretanto enganar com isso; pois declara sua própria ocupação como um mero jogo" (Kant, 1980, p. 1980). Na afirmação kantiana, o ponto importante consiste em que, na poesia, o jogo com a aparência não engana. Mas o sentido pelo qual esse jogo não engana na poesia só se esclarece, no contexto da afirmação kantiana, pelo contraponto que ele estabelece com a "eloquência": na qualidade de "ars oratoria", a eloquência se vale da "bela 
aparência" para "ludibriar"(Ibid.). Assim, poder-se-ia dizer que, para Kant, a aparência poética é um jogo de representações que não engana na poesia, mas engana na eloquência. Ora, como dificilmente Schlegel concordaria com um juízo tão negativo da arte retórica - tanto que, no célebre fragmento 116, ele defende o contato da filosofia com a retórica - e como Kant não explicita o conceito de aparência aí envolvido, fica difícil levar essa apropriação conceitual mais adiante. Mas além da inspiração kantiana, a afirmação lapidar acima referida pode ser esclarecida por um dos Fragmentos sobre literatura e poesia I, escritos entre 1797-98. Após a mesma frase que estamos analisando, lêse ainda: "Prazer [Lust] é a matéria da impressão artística; jogo e aparência são a forma. Prazer é consciência da animalidade potencializada. < Sentido é vida potencializada, dividida. >" (Schlegel, 1980, p. 43). Sob o prisma desse acréscimo, a receptividade envolvida na aparência poética se explicita em termos de uma "impressão artística" que engendra o "prazer" como matéria. Como esse prazer é definido em termos de uma "consciência da animalidade", talvez se possa dizer que se trata de um prazer simultaneamente sensível e espiritual, na medida em que nele parecem concorrer virtuosamente a animalidade dos sentidos e a espiritualidade. Assim, a impressão artística faz com que a vida humana, dividida entre animalidade e espiritualidade, ganhe força, intensidade e vivacidade pelo puro prazer das aparências poéticas.

Mas o delineamento geral da imagem da linguagem poética em Schlegel só se completa quando as linhas que o vinculam ao paradigma idealista da estética kantiana encontram um componente absolutamente clássico e aristotélico: o conceito de "verossímil" [Wahrscheinlich]. Em pleno período de uma tensão aguda 
entre os modelos neoclássicos e as visões românticas da estética, e no mesmo ano em que também Goethe publica o diálogo "Sobre verdade e verossimilhança das obras de arte" (Goethe, 2008, pp. 134-148), Schlegel decide acolher o conceito em seu arcabouço e acomodá-lo ao contexto da estética idealista. À luz dessa perspectiva, dois aspectos, que também estão presentes nas discussões do escrito de Goethe, caracterizam o tratamento da questão: o aspecto sob o qual se pensa a representação poética em relação à realidade; e aquele no qual se considera o tipo de crença que o receptor tem em relação ao que é representado. Na Athenäum 101, Schlegel afirma: "Aquilo que acontece na poesia, ou não acontece nunca, ou acontece sempre. Do contrário, não é verdadeira poesia. Não se pode ser obrigado a acreditar que esteja efetivamente acontecendo agora."

É importante compreender como esse fragmento pode complementar a concepção da aparência poética: ela é um jogo de representações enquanto expressão do verossímil. Embora não seja utilizado o termo 'verossímil' nesse fragmento, o que é dito sobre "o que acontece na poesia" recobre perfeitamente o conceito de "verossímil" tratado no fragmento 74 da Athenäum. Neste, Schlegel nega que "verossímil" significa o que é "aproximadamente verdadeiro", ou "um tanto verdadeiro", ou "aquilo que talvez um dia ainda possa se tornar verdadeiro". Segundo ele, essa palavra "não pode designar nada disso", pois "verossímil" deve significar positivamente "o que parece verdadeiro" [was wahr scheint]. O verossímil não é como um paliativo de um verdadeiro que não se pode ter, nem substituto de um original. O "parecer verdadeiro" não está abaixo do "ser verdadeiro", porque, não estando a serviço da representação dos fenômenos da natureza e do mundo, não pode ter a mesma natureza das verdades 
das ciências. O verossímil deve, pois, ter critérios próprios de significação e um domínio autônomo de validade no qual o verdadeiro factual, em sua especificidade apofântica, não lhe dita as regras.

Ora, "o que acontece" na poesia é uma "aparência", um jogo de representações. Mas é um jogo no qual "não se pode ser obrigado a acreditar" que aquilo que acontece corresponda ao que "esteja efetivamente acontecendo agora" - Kant disse que a aparência poética não engana. Schlegel reforça a ideia de que a esse jogo de representações não cabe pressupor nenhum tipo de correspondência entre o que é representado e o acontecer efetivo e atual, precisamente porque nele as representações não têm qualquer intenção de exprimir verdades factuais, pontuais, presentes e determinadas, enfim, "o que está acontecendo agora". Isso não significa, porém, que não possa haver um outro tipo de relação entre "o que acontece na poesia" e o acontecer em geral. Pois Schlegel diz que "o que acontece na poesia" (a) "ou não acontece nunca", (b) "ou acontece sempre". Bem se pode defender a ideia de tratar-se aqui da diferença entre um conceito de "verdade", entendida como empírica, atual e determinada - fenomenal -, e o conceito de "verossímil" que envolve tanto o sempre quanto o nunca do acontecer. Pois, como ele é definido como o "parecer verdadeiro", sem precisar, contudo, ser verdadeiro "sequer em grau mínimo", isso significa o seguinte: se o representado "nunca" acontece, isso não o impede de ser verossímil; reciprocamente, se ele "sempre" acontece, isso não o torna verdadeiro. Juntando o elemento clássico ao modelo idealista romântico, teríamos algo mais ou menos assim: a aparência - ou ilusão poética é um jogo de representações que segue a gramática do verossímil. Ora, como se sabe desde Aristóteles, o verossímil 
[eikos] é componente teórico fundamental à poética e à retórica, sendo por isso também um conceito que sempre sofreu muitas modificações quando apropriado por distintas tradições. Assim, com as indicações gerais que aqui se fazem, pretende-se apenas apontar para o terreno por onde passariam as corretas formulações do problema de tentar combinar o conceito clássico do verossímil com o conceito idealista de "aparência" [Schein].

No que segue, examinaremos dois fragmentos do Lyceum que apontam para uma direção mais clara na exploração conceitual do logos poético schlegeliano. Não por acaso, são textos que nos permitem vislumbrar uma combinação do ponto de vista da poesia com o ponto de vista da filosofia. No primeiro texto encontra-se a afirmação da poesia como um "discurso republicano", e no segundo, uma irônica crítica ao conceito kantiano de "entendimento discursivo". Comecemos pelo primeiro: "A poesia é um discurso republicano; um discurso que é sua própria lei e seu próprio fim, onde todas as partes são cidadãos livres e têm direito a voto." (Schlegel, 1967, p. 155)

Que o discurso da poesia seja "sua própria lei e seu próprio fim" e que ele se caracterize como um locus em que "todas as partes são cidadãos livres" com "direito a voto" são exigências que devem ser consideradas cruciais para o tipo de "autonomia" que Schlegel quer atribuir às expressões poéticas. Aqui, como na teoria kantiana da arte, não se trata de professar a ausência de regras, mas em garantir a liberdade de instituí-las e de modificá-las: trata-se, pois, de uma república sintática e não de uma anarquia (a menos que se pense numa anarquia metódica e provisória). O discurso é autônomo na exata medida em que é republicano, e somente assim poderá estabelecer a sua finalidade e as leis do seu próprio regimento: o "regime" sintático ou 
gramatical deve ser "decidido" pelas partes num jogo de completa isonomia entre elas. Ora, não estaria essa concepção em perfeita sintonia com os aspectos da "heautonomia" da reflexão, que Kant afirma na Crítica do Juízo?

Entretanto, se esta for uma via possível de exploração, ela deve também incorporar o tipo de reparo que Schlegel sugere à concepção do caráter discursivo do entendimento na Crítica da Razão Pura. Eis como ele aponta uma falha e propõe um acréscimo à famosa tábua das categorias: Na árvore genealógica dos conceitos primordiais de Kant sinto com desagrado a falta da categoria "aproximadamente", que todavia com certeza provocou, no mundo e na literatura, o mesmo tanto de efeitos e de estragos que qualquer outra categoria. No espírito dos céticos naturais, ela tinge todos os demais conceitos e intuições.(Schlegel, 1997, p. 32)

Conforme nota de Márcio Suzuki a esse fragmento, em outra edição dos fragmentos Schlegel também se refere às categorias "por assim dizer" e "talvez" (Ibid, nota 54). Levando isso em conta, as categorias faltantes seriam o "aproximadamente" [Beinahe], o "por assim dizer" [Gleichsam] e o "talvez" [Vielleicht]. Como se sabe, ao apresentar a célebre tábua das categorias na Crítica da Razão da Pura, Kant afirma que elas foram derivadas das formas lógicas dos juízos, que são "funções de unidade" ou de síntese (Kant, 1994, p. 110). Há, pois, tantas categorias quantas funções lógicas existem em todos os juízos possíveis. Kant considera que a tábua das categorias dispõe, de maneira organizada, todos os "conceitos originais e primitivos" do entendimento, sugerindo que isso facilitaria o trabalho de acrescentar os conceitos "derivados e subalternos" para "desenhar totalmente a árvore genealógica do entendimento puro"; e diz claramente o seguinte: 
"Como aqui não me proponho a apresentar um sistema completo, mas tão-só os princípios com vistas a um sistema, deixo para outro ensejo este aperfeiçoamento"(Ibid., p. 112). Ora, sabemos o quanto essa tábua foi alvo de crítica entre os herdeiros fiéis a Kant. Contudo, o que destaca Schlegel entre tantos outros críticos é que na irônica proposta de completá-la ele acaba por desestabilizá-la, incluindo o que podemos chamar de uma categoria não-determinante à própria árvore genealógica da determinação.

As categorias são formas de estruturar e ordenar o conhecimento empírico dos objetos; correspondem a determinações formais do pensamento, a modos de operar com as representações, de unir umas com as outras - no vocabulário de Kant: são funções de síntese, isto é, funções de julgar - e estruturam o entendimento enquanto faculdade discursiva (e não intuitiva). Ao dizer que entre as categorias elencadas por Kant sentiu "com desagrado" a falta da categoria "aproximadamente", Schlegel pretende provocar um tremor na força determinante das operações originais e primitivas do entendimento, como se quisesse realçar ali a operação da reflexão. Ele introduz positivamente uma categoria cuja forma de ligação ou síntese correspondente representaria melhor, a seu ver, a gramática do pensamento humano. Ora, é óbvio que o "aproximadamente" schlegeliano carrega certo grau de indeterminação. Seria de fato cômico se os termos "aproximadamente", "como que" e "por assim dizer" formassem, juntos, um quinto grupo de categorias a ser acrescentado aos outros quatro grupos de três já existentes. Mas a sugestão de Schlegel consiste em fazer o "aproximadamente" funcionar como uma espécie de operação contra-determinante do pensamento em geral, que viria acompanhar a aplicação de todas as outras categorias. 
Isso é sugerido no próprio fragmento, quando ele diz que "no espírito dos céticos naturais, ela tinge todos os demais conceitos e intuições".

Neste caso, teríamos a indicação de algo vago e indefinido nas próprias formas lógicas do julgar das quais derivariam, genealogicamente, todas as outras, e isso viria instaurar concretamente certa vagueza ou abertura semânticas onde a letra de Kant parece ter enfatizado um regime de estrita determinação. Do ponto de vista cognitivo, a consequência é bastante simples: o juízo produzido por obra dessa categoria resistiria à fixação decisiva de valores de verdade, pela inexatidão e falta de completude dos significados e - consequentemente - pela possibilidade de se pensar em uma outra operação possível de síntese num mesmo ato de julgar. Teríamos, então, na árvore genealógica, uma categoria cuja função seria a de instaurar certa vagueza aproximativa constitutiva nas formas do entendimento, isto é, certo grau de indeterminação formal (por menor que seja) de toda a experiência possível. É bastante relevante o fato de Schlegel propor uma paradoxal categoria reflexionante na tábua lógica dos juízos que, na terceira crítica, são designados como determinantes. É uma pena que Walter Benjamin, que o tempo todo fala na "teoria do conhecimento" de Schlegel, tenha deixado passar em branco esse fragmento. Pois assim como o "aproximadamente" indica graus de aproximação do sentido, o "por assim dizer" permite introduzir semelhanças e analogias - o "como que" poderia inclusive ser entendido como uma modalidade do "como se" - e o "talvez" dá lugar a graus de dúvida ou incerteza. Juntas, tais "categorias" indicariam um pensamento recalcitrante à função determinante, no próprio âmbito cognitivo dos conceitos e das intuições. 
Ora, combinando a concepção da poesia como "discurso republicano" e a concepção das "sínteses aproximativas" do entendimento, compreende-se como o logos poético pode, em Schlegel, promover a aproximação da poesia com a filosofia e com a retórica. Pode-se dizer que os aspectos agora apontados também fundamentam as discordâncias de Schlegel quanto à linguagem que os filósofos utilizam para escrever filosofia, especialmente quando adotam métodos de exposição que impõem à razão uma figura sempre inadequada porque ilegítima. A autonomia da sintaxe, que faz jus ao livre jogo das conexões e das sínteses aproximativas, sustenta e é sustentada pela visão de que "os pensamentos são, em sua maioria, apenas perfis de pensamentos" (Schlegel, 1967, p,.171); e de que "pensamentos entremesclados deveriam ser os esboços da filosofia", na medida em que nos permitem "rascunhar mundos filosóficos a lápis" (Ibid., p. 216). A autonomia da sintaxe também fundamenta a crítica a um "modo de pensar de alguns filósofos" que convocam e reúnem suas ideias como se organizassem um regimento militar, impondo-lhes rigidez, inflexibilidade e total obediência à autoridade estruturadora de um sistema (Ibid., p. 172), assim como a crítica às demonstrações, deduções e definições(Ibid., p. 177). E muitas outras afirmações. Mas eu gostaria de enfatizar especialmente uma: Algumas coisas a filosofia tem provisoriamente de pressupor para sempre, e é lícito que o faça, porque o tem de fazer (Ibid, p,.179).

Só pode ser eternamente "por enquanto" ou "provisório" aquilo que não poderia de ser de outra maneira. Essa parece ser uma indicação metodológica que vai na contramão da atitude filosófica que busca fundamentos últimos, e, nessa medida, Schlegel parece defender o emprego de uma pressuposição eternamente 
provisória, vista como necessária à escritura filosófica. Tal pressuposição poderia valer para sempre sem jamais perder seu caráter universal. Ora, não seria da natureza própria do pensamento transcendental que ele seja uma pressuposição eternamente provisória? Provisório não no sentido de que lhe faltaria a confirmação ou de que um dia pudesse vir a ser verificado, mas no sentido de uma provisoriedade eternamente aberta ao infinito poder de atualização. Não seria a pressuposição transcendental, então, um eterno verossímil? Se pudermos fazer essa aproximação, seria essa uma outra maneira de pensar a ligação entre "o que acontece" na poesia e aquilo que a filosofia diz que acontece na nossa razão. E se isso puder também ser demonstrado, talvez possamos dizer que também a filosofia - que cada filosofia - é uma mímesis da razão. ${ }^{4}$

\section{Referências bibliográficas}

BENJAMIN, W. O conceito de crítica de arte no romantismo alemão. Trad., introd e notas de Márcio Selligmann-Silva, São Paulo: Iluminuras, 2002.

GOETHE, J. W. "Sobre verdade e verossimilhança da obra de arte (1798)". In: Escritos sobre a arte: Johann Wolfgang Goethe. Trad., introd. e notas de Marco Aurélio Werle, São Paulo: Humanitas/Imprensa Oficial, 2008.

KANT, I. "Analítica do belo". Trad. de Rubens Rodrigues Torres Filho. In: Crítica da Razão Pura e outros textos filosóficos, São Paulo: Ed. Abril, 1980.

${ }^{4}$ Este trabalho é resultado de pesquisa financiada pela Coordenação de Aperfeiçoamento de Pessoal de Nível Superior - CAPES. 
. "Da arte e do gênio". Trad. de Rubens Rodrigues Torres Filho. In: Crítica da Razão Pura e outros textos filosóficos, São Paulo: Ed. Abril, 1980.

- Crítica da Razão Pura. Trad. de Manuela p. dos Santos e Alexandre Morujão, Lisboa: Calouste Gulbenkian, 1994.

SCHLEGEL, Friedrich. O dialeto dos fragmentos. Trad., apres. e notas de Márcio Suzuki, São Paulo, Iluminuras, 1997.

Kritische Friedrich Schlegel Ausgabe. Edição crítica das obras de F. Schlegel, editadas por Ernst Behler. Paderborn/Munique/Viena: Ferdinand Schöningh, vols. I e II., 1967.

Conversa sobre a poesia. Trad. de Márcio Suzuki e Constantino Luz de Medeiros, São Paulo: Ed. (no prelo). " "1797-98: Fragmente zur Litteratur und Poesie I". In: FRIEDRICH SCHLEGEL, Literarische Notizen 1797-1801 Literary Notebooks. Edição de Hans Eichner, Frankfurt/M Berlin - Wien: Ullstein Materialien, 1980.

SUZUKI, Márcio. O gênio romântico. São Paulo: Iluminuras, 1998.

. "A gênese do fragmento", In: SCHLEGEL, Friedrich. O dialeto dos fragmentos. Trad., apres. e notas de Márcio Suzuki, São Paulo, Iluminuras, 1997. 